\title{
OBSERVACIÓN JURISPRUDENCIAL RELATIVA A LA LEY APLICABLE A LA COMPRAVENTA DE BIENES INMUEBLES RADICADOS EN EL EXTRANJERO. ESTUDIO DE CASO A PARTIR DE LA SAP DE MURCIA, NÚM. 98/2020
}

\author{
JURISPRUDENTIAL VIEW IN RESPECT OF THE APPLICABLE \\ LAW TO THE SALE OF IMMOVABLE PROPERTY LOCATED \\ ABROAD. CASE STUDY ACCORDING TO JUDGMENT \\ OF THE PROVINCIAL COURT OF MURCIA, N 98/20
}

\author{
DAVID CARRIZO Aguado \\ Profesor Ayudante Doctor de Derecho internacional privado \\ Universidad de León
}

ORCID ID: 0000-0002-9427-287X

Recibido: 00.00.2010 / Aceptado: 00.00.2010

DOI: https://doi.org/10.20318/cdt.2021.5988

\begin{abstract}
Resumen: A la luz de este pronunciamiento, el juez español viene a aclarar que, al amparo de la Ley preconstitucional 57/1968, de 27 de julio, no quedarán protegidos aquellos compradores que adquieran una vivienda con un fin no residencial. En concreto, considera que deben de excluirse los adquirentes que aun siendo personas físicas, compren la vivienda con un propósito inversionista, considerando como tales a los profesionales del campo inmobiliario. De igual modo, los particulares que sin ser profesionales del sector, invierten en la compra de viviendas en construcción para revenderlas durante el proceso de edificación o a su finalización. En concordancia con esta idea, resulta significativo valorar la eficacia del pacto de Ley inserto en un contrato de compraventa de un bien inmueble situado en el extranjero y, reflexionar en torno a la catalogación de consumidor en un marco difuso, asentado por la práctica habitual de inversión en el tráfico jurídico externo.

Palabras clave: Derecho aplicable, autonomía de la voluntad conflictual, inversiones transnacionales, bien inmueble sito en el extranjero, consumidor vs. inversor.

Abstract: With this judgment, the Spanish Judge clarifies that, under the preconstitutional 57/1968 Law, of July 27 , those buyers who acquire a home for a non-residential purpose will not be protected, and specifically, it considers that they must to exclude those purchasers who, although they are individuals, buy the home with an investment purpose, considering as such those professionals in the real estate field, or those individuals who, without being professionals in the sector, invest in the purchase of homes under construction to resell them during the building process or upon completion. In accordance with this idea, it is significant to assess the effectiveness of the Law covenant inserted in a contract for the sale of an asset located abroad and to reflect on the consumer cataloging in a diffuse framework generated by the usual practice of investment in this type of real estate in foreign legal traffic.
\end{abstract}

\footnotetext{
*Este trabajo se ha realizado en el marco del proyecto de investigación emergente $\mathrm{I}+\mathrm{D}+\mathrm{i}$ financiado por la Generalitat Valenciana (con referencia GV/2019/118) titulado "La tutela de los derechos en el entorno digital: nuevos retos, desafíos y oportunidades", Investigador Principal José Juan Castelló Pastor del que el autor es miembro del grupo de investigación.
} 
Keywords: applicable law, autonomy of the will, transnational investments, immovable property located abroad, consumer vs. investor.

Sumario: I. Aspectos destacables en los hechos controvertidos. 1. Punto de partida. 2. Descripción de la situación fáctica. II. La autonomía de la voluntad en sede de Derecho aplicable. 1. Prospectiva inicial. 2. Valoración del pacto conflictual. 3. Beneficios conflictuales. III. Indicios de la actividad inversora del comprador ¿pérdida de la condición de consumidor? 1. Nota preliminar. 2. Categorización de consumidor al albor europeo. 3. Denominador común en la práctica judicial española.

\section{Aspectos destacables en los hechos controvertidos}

\section{Punto de partida}

1. La cuestión fáctica que alberga la SAP de Murcia, de 20 de abril de $2020^{1}$ gira en torno a diversos hechos que merecen ser puestos de relieve para comprender el enredado escenario jurídico de este asunto litigioso.

Así las cosas, siendo la parte demandante en el proceso de apelación el Banco Santander, y demandados D. Jon y Dña. Genoveva, el objeto del recurso se articula, esencialmente, en base a dos cuestiones que serán analizadas a lo largo de este estudio al resultar de sumo interés desde una perspectiva internacional privatista.

2. De este modo, se abordarán, de un lado, la eventual inaplicación de la Ley 57/1968, de 27 de julio, sobre percibo de cantidades anticipadas en la construcción y venta de viviendas ${ }^{2}$, al ser la norma elegida por las partes como consecuencia de la existencia de un elemento extranjero, las viviendas adquiridas situadas fuera del Estado español, y, de otro, la consideración en tanto que los compradores de las mismas pueden ser tratados en calidad de consumidores al denotarse una posible actividad inversora.

\section{Descripción de la situación fáctica}

3. En el año 2006 se suscribieron en la ciudad de Murcia sendos contratos de reserva de inmueble en construcción entre la sociedad brasileña Lagoa Do Coelho Emprendimientos Turísticos Ltda, con domicilio social en Natal, Estado de Rio Grande do Norte (Brasil), representada por la sociedad española Grupo Nicolás Mateos SL, siendo esta parte la que actúa como vendedora, y los compradores D. Jon y $\mathrm{D}^{\mathrm{a}}$ Genoveva. Dichas reservas se realizaron en relación a la promoción denominada "Lagoa do Coelho Resort" cuya construcción estaba prevista en terrenos de su propiedad situados en el municipio de Touros, Natal, Estado de Rio Grande de Norte (Brasil).

4. Los contratos privados de compraventa sobre dos viviendas se celebraron en la ciudad de Murcia, residencia de los compradores. A los efectos que aquí interesan, en ambos contratos se estipulan, entre otras cláusulas, la siguiente: el contrato queda sometido a las leyes españolas para todas las cuestiones relacionadas con la existencia, cumplimiento, validez, ejecución e interpretación, excepto para aquellas cuestiones relacionadas con la transferencia de la propiedad, para las cuales se regiría por las leyes brasileñas. Además, como dato distinguido que será tratado en el epígrafe III, los actores son propietarios de diversos inmuebles en España, sin que su actividad empresarial guarde relación alguna con el mercado inmobiliario.

\footnotetext{
${ }^{1}$ ES:APMU:2020:647

${ }^{2}$ BOE núm. 181, de 29 de julio de 1968.
} 
5. A razón del episodio fáctico, en los siguientes apartados se afrontará, por una parte, la eficacia del pacto en una relación transfronteriza cuyo objeto litigioso es el incumplimiento de un contrato de compraventa, y de otra, la calificación de la condición de consumidor como contrapunto al elemento teleológico de la adquisición de las viviendas sitas en el extranjero con finalidad inversionista.

\section{La autonomía de la voluntad en sede de Derecho aplicable}

\section{Prospectiva inicial}

6. Tal y como se ha expuesto en el relato de hechos, las partes acuerdan aplicar el Derecho español en todo lo concerniente al cumplimiento y validez del contrato. Se denota que la principal controversia deriva de un incumpliendo de la obligación legal impuesta por el apartado segundo, del artículo 1 de la Ley $57 / 1968$.

Si bien, se trata de un bien situado en el extranjero, concretamente fuera de la Unión Europea, Brasil, constituyendo este el único elemento extranjero presente en la relación jurídica, ya que los compradores son de nacionalidad española y el contrato se firma en España con una sociedad española.

\section{Valoración del pacto conflictual}

7. En virtud de la libertad de pacto conferida por el artículo $1255 \mathrm{CC}^{3}$, existen elementos o conexiones suficientes para justificar la validez del mismo ${ }^{4}$. En cualquier caso, no cabe pretender que un contrato se regule totalmente al margen de cualquier ley estatal, incluso en aquellos supuestos en los que se pacta la sumisión del mismo a usos, costumbres o convenios internacionales ${ }^{5}$.

En este sentido, la autonomía conflictual ${ }^{6}$, faculta a las partes a elegir como Ley aplicable al contrato, la Ley de un Estado?.

8. Ciertamente, en los contratos internacionales la autonomía de la voluntad adquiere una dimensión más amplia que la mera facultad de las partes para establecer, de común acuerdo, el contenido de sus contratos, pues les permite sustraerse de las normas consideradas inderogables en los Estados, con los cuales se vinculan sus relaciones mediante un acuerdo de elección de Ley8.

\footnotetext{
${ }^{3}$ Con el fin de evitar que la libertad de los individuos en el ámbito de la contratación fuera desmesurada, el propio artículo 1255 CC consagra la superioridad del interés general sobre el particular, al proclamar la imposibilidad de llevar a cabo acuerdos de voluntades contrarios a la ley, la moral y el orden público. La limitación de dicha libertad tiene un carácter tuitivo al anteponer las necesidades sociales al individuo (Vid. M. SEDA Mora, "Autonomía de la voluntad y crisis económica: nuevas oportunidades y limitaciones”, en C. Hornero Méndez / M. Espejo Lerdo de Tejada y F. Oliva Blázquez (dirs.), Derecho de contratos: nuevos escenarios y nuevas propuestas, Thomson Reuters Aranzadi, Navarra, 2016, libro electrónico).

${ }^{4}$ C. Esplugues Mota, "Obligaciones Contractuales: régimen general”, en C. Esplugues Mota / J.L. Iglesias Buhigues y G. Palao Moreno, Derecho Internacional Privado, 14a ed., 2020, Tirant lo Blanch, Valencia, p. 639.

${ }^{5}$ R. Bercovitz Rodríguez-Cano, “Artículo 10.5”, en R. Bercovitz Rodríguez-Cano (coord.), Comentarios al Código Civil, $4^{\text {a }}$ ed., 2013, libro electrónico.

${ }^{6}$ Se utiliza la expresión autonomía conflictual para definir la posibilidad que tienen las partes contratantes de elegir la ley rectora del contrato que va a determinar la validez, alcance y efectos de todos y cada uno de los pactos suscritos por las partes: cfr. J.C. Fernández Rozas y S. SÁnchez LoRenzo, Derecho Internacional Privado, $11^{\mathrm{a}}$ ed., Civitas Thomson Reuters, Navarra, 2020, p. 643.

${ }^{7}$ La tendencia favorable a la autonomía de la voluntad conflictual se impone en toda Europa y ya desde el siglo XIX queda claro que el primer punto de conexión para designar la Ley reguladora de los contratos internacionales es la autonomía de la voluntad de los contratantes. Así, el contrato debe regirse por la Ley estatal determinada por las partes (Cfr. J. CARRASCOSA GonzÁlez, "La autonomía de la voluntad en la contratación internacional", en L. Prats Albentosa (coord.), Autonomía de la voluntad en el derecho privado. Estudios en conmemoración del 150 aniversario de la Ley del Notariado, Vol. 5, Wolters Kluwer, Madrid, 2012, pp. 620-621).

${ }^{8}$ Ahora bien, existen un número importante de normas que limitan el ejercicio de la autonomía de la voluntad conflictual. Esto es, cada Estado antepone a la autonomía de la voluntad, las normas imperativas que salvaguardan el propio mercado o que tratan de garantizar el equilibrio de las partes contratantes y su buen fin (Vid. C. VAQuero López, "Autonomía de la voluntad y
} 
9. Se trata de una elección genérica e incondicional del Derecho de las obligaciones de un determinado sistema jurídico estatal y se presupone que esa amplitud del juego solo se justifica cuando las partes operan en el mercado internacional ${ }^{9}$. Más aún, carece de sentido concebir la autonomía conflictual como medio de designación de una Ley aplicable estatal orientada a delimitar el alcance de la autonomía material ${ }^{10}$. En consecuencia, se entiende que, la fuerte tendencia hacia la internacionalización de la actividad humana y las diversas controversias que pudieran surgir, comportaría la conveniencia de trasladar a las partes la capacidad de atender a sus propios intereses en la gestión jurídica de sus litigios ${ }^{11}$.

10. En opinión de un sector doctrinal, la falta de armonización internacional suficiente del Derecho de los contratos ${ }^{12}$ implica un marco de inseguridad que solo puede ser resuelto al abrigo de un principio tan elemental como el pacta sunt servanda, pues en el tráfico comercial predomina universalmente el principio de autonomía de la voluntad ${ }^{13}$. Asimismo, la voluntad de las partes no tiene un valor jurídico originario, sino que su poder vinculante deriva de la fuerza que le asigna un ordenamiento jurídico, a partir de un planteamiento básico ${ }^{14}$.

\section{Beneficios conflictuales}

11. En los contratos internacionales, las partes pueden utilizar el principio de autonomía de la voluntad para escoger la Ley que les sea más favorable a los objetivos perseguidos y evitar que los sistemas legales frustren dichos objetivos ${ }^{15}$. Ahora bien, dado que la aspiración de la cláusula sobre elección de Ley aplicable es concretar la legislación rectora del contrato, la remisión se entiende típicamente formulada a la legislación material del país designado y no a las normas de conflicto de leyes de ese ordenamiento jurídico, de modo que el reenvío no operará en estos supuestos ${ }^{16}$.

normas imperativas", en S. SÁnchez LoREnzo (ed.), Derecho contractual comparado. Una perspectiva europea y transnacional, $2^{a}$ ed., Civitas Thomson Reuters, Navarra, 2016, pp. 896-897). Por tanto, las leyes de policía prevén la posibilidad para el juzgador de descartar la ley elegida por las partes si no respeta las reglas básicas para su país; estas normas son representativas de los valores básicos de la organización social y económica de un Estado y su aplicación requiere de una imperatividad reforzada que trasciende a la aplicación de un concreto ordenamiento (Vid. E. Gómez Valenzuela, "Normas imperativas y deberes de información en la contratación electrónica", Revista Aranzadi de derecho y nuevas tecnologías, núm. 49, 2019, versión on line).

${ }^{9}$ Solo es admitida por el legislador en los contratos internacionales, no en los internos ( $C f r$. F.J. GarcimarTín Alférez, Derecho Internacional Privado, $5^{\text {a }}$ ed., Civitas Thomson Reuters, Navarra, 2019, p. 360).

${ }^{10}$ De ahí que, en la contratación internacional, la demarcación del alcance de la autonomía material debe realizarse exclusivamente a través del juego de las normas imperativas, tanto de la lex causae como de la ley del foro (Cfr. S. SÁnCHEz LoRENZo, Abogacía internacional Volumen III: Contratos, Rasche, Madrid, 2014, p. 162).

${ }^{11}$ Magistralmente, el Dr. Guillermo Palao Moreno realiza un estudio en profundidad sobre la irrupción del principio de autonomía de la voluntad en el ámbito de los conflictos transfronterizos de naturaleza privada. Vid in extenso, "La autonomía de la voluntad y la resolución de las controversias privadas internacionales", en L. Prats Albentosa (coord.), Autonomía de la voluntad en el derecho privado. Estudios en conmemoración del 150 aniversario de la Ley del Notariado, Vol. 5, Wolters Kluwer, Madrid, 2012, pp. 817-956, esp. pp. 824-828.

${ }^{12}$ No se trata de elaborar un código de Derecho contractual europeo destinado a sustituir al Derecho nacional, sino únicamente ofrecer a los agentes económicos un modelo de regulación contractual más moderno, coherente y ajustado a las necesidades del mercado interior: vid. en este sentido, N. BouZA I VIDAL, "La elección conflictual de una normativa no estatal sobre contratos internacionales desde una perspectiva europea”, en AA.VV., Pacis Artes. Obra homenaje al profesor Julio D. González Campos, Vol. II, Edifer, Madrid, 2005, p. 1312.

${ }^{13}$ Las normas internacionalmente imperativas que limitan dicha autonomía son fácilmente reconocibles y las partes pueden predecir la aplicación de normas que limitan dicha autonomía, tanto internas, como internacionales o supranacionales, y en particular las que se derivan de los sistemas jurídicos más próximos: la ley del tribunal elegido, la ley del país de ejecución o la ley del mercado afectado: vid. S. SÁnchez Lorenzo, "Contrato interno e internacional: claves de la diferencia”, en C. Hornero Méndez / M. Espejo LeRdo de Tejada y F. Oliva Blázquez (dirs.), Derecho de contratos: nuevos escenarios y nuevas propuestas, Thomson Reuters Aranzadi, Navarra, 2016, libro electrónico.

14 P.A. De Miguel Asensio, "Contratación comercial internacional”, en J.C. Fernández Rozas, R. Arenas García y P.A. DE Miguel Asensio, Derecho de losnegocios internacionales, $6^{\text {a }}$ ed., Iustel, Madrid, 2020, libro electrónico.

${ }^{15}$ M. Fontaine y F. DE Ly, La redacción de contratos internacionales. Análisis de causas, Thomson Reuters, Navarra, 2013, libro electrónico.

${ }^{16}$ Para evitar cualquier incertidumbre sobre este particular se suele precisar de manera expresa al prever que la elección de 
12. De hecho, las partes están mejor posicionadas que el juez para decidir qué Ley estatal les comporta menores costes conflictuales. La autoridad judicial no debe sustituir a los particulares cuando estos pueden decidir por sí mismos, por un sencillo motivo: el juez no cuenta, a priori, con los datos subjetivos particulares, propios de concretos sujetos individuales, y no generalizables, que le permiten valorar cuál es la Ley que comporta costes menores para dicha persona ${ }^{17}$.

13. Sea como fuere, las partes contratantes deben disponer de unas reglas de comportamiento cuya aplicación les comporte costes reducidos y que puedan conocer ex ante las consecuencias legales de sus comportamientos contractuales ${ }^{18}$. Dicho criterio proporciona una previsibilidad máxima de la Ley aplicable y, además, supone un criterio intrínsecamente eficiente ${ }^{19}$.

14. En suma, la elección de la Ley aplicable al contrato por los particulares implicados entraña, con carácter general, la continuidad en la decisión adoptada por los sujetos intervinientes, evitando la aplicación de una Ley que beneficie solamente a una parte contratante dotando al mismo de certeza y previsibilidad, dado que las partes contratantes conocerán anticipadamente la Ley que regula el contrato en caso de una controversia ${ }^{20}$.

Por ende, a la hora de cerrar un contrato internacional es de vital importancia la identificación de la Ley que va a regir el contrato. Esa Lex contractus va a venir determinada por un punto de conexión que es la "autonomía de la voluntad" constituyendo esta, el derecho subjetivo del que disponen los contratantes para poder elegir la Ley que regula el contrato del que participan ${ }^{21}$.

\section{Indicios de la actividad inversora del comprador ¿pérdida de la condición de consumidor?}

\section{Nota preliminar}

15. Naturalmente, la protección de los consumidores responde a la necesidad de equilibrar situaciones jurídicas donde una de las partes está en situación de inferioridad con respecto a la otra parte ${ }^{22}$.

En el ámbito del Derecho privado, encontramos normas específicas dirigidas a la protección de los consumidores, que disciplinan la intervención de dichos sujetos en el ámbito de la contratación

la Ley de un país como Ley del contrato tiene lugar «con exclusión de sus reglas de Derecho internacional privado (Cfr. P.A. De Miguel Asensio, "Cláusulas de elección del derecho aplicable", en S. SÁnchez Lorenzo (coord.), Cláusulas en los contratos internacionales: redacción y análisis, Atelier, Barcelona, 2012, p. 250).

${ }^{17}$ J. CARrascosa GonzéLez, "La autonomía de la voluntad conflictual y la mano invisible en la contratación internacional", Diario La Ley, núm. 7847, 2012.

${ }^{18}$ A-L. Calvo Caravaca y J. Carrascosa González, "Contratos Internacionales I", en A-L. Calvo Caravaca y J. Carrascosa González (dirs.), Tratado de Derecho Internacional Privado, Tomo II, Valencia, Tirant lo Blanch, 2020, p. 177.

${ }^{19}$ Se podrá elegir la Ley estatal cuyo contenido material sea más favorable para los particulares (Vid. A-L. CALvo CaravaCA, "La norma de conflicto en el siglo XXI", en AA.VV., Pacis Artes. Obra homenaje al profesor Julio D. González Campos, Vol. II, Edifer, Madrid, 2005, pp. 1372-1373.

${ }^{20} \mathrm{M}^{\mathrm{a}}$. D. Ortiz Vidal, Ley aplicable a los contratos internacionales y eficiencia conflictual, Comares, Granada, 2014, pp. 71-72.

${ }^{21}$ A. Ortega GimÉnez, "Los contratos internacionales y la autonomía de la voluntad conflictual ante el Tribunal Supremo", en A-L. Calvo Caravaca y J. Carrascosa González (coord..), El Tribunal Supremo y el derecho internacional privado, Vol. 1, Rapid Centro Color, Murcia, 2019, pp. 261-281.

${ }^{22}$ El consumidor se contenta la mayor parte de las veces con sufrir la voluntad del profesional que manifiesta todo su poder; este difícilmente se encuentra en situación de negociar, de discutir el contenido del contrato que habrá sido preredactado por el profesional. Pero también, el consumidor puede llegar a ser igualmente protegido contra sí mismo, su vulnerabilidad se está viendo acrecentada por una cierta complacencia que le conduce a veces a la docilidad, vid. G.A. BotanA García, "La protección del consumidor como cliente bancario", Actualidad civil, núm. 5, 2016, versión online; C. Rojo Álvarez-Manzaneda, "La normativa de protección al consumidor como vía de tutela del cliente inversor", Práctica derecho daños: Revista de Responsabilidad Civil y Seguros, núm. 122, 2015, pp. 42-55; J. BARCeló DomÉNeCH, "Relaciones entre el Derecho de la Unión Europea y Derecho nacional en materia de contratación bajo condiciones generales", en C.C. CAstillo Martínez (dir.) y J.L. Fortea Gorbe (coord.): Jurisprudencia sobre hipotecas y contratos bancarios y financieros. Análisis de la jurisprudencia reciente sobre préstamos, créditos, cláusulas de préstamos hipotecarios, contratos bancarios, tarjetas, productos financieros y usura, Tirant lo Blanch, Valencia, 2019 , p. 27. 
de variados servicios que al hallarse fuera de su lugar de origen se encuentran en una posición de clara inferioridad. Por consiguiente, es necesaria una protección jurídica específica para aquellas situaciones contractuales que están conformadas por éstos ${ }^{23}$.

\section{Categorización de consumidor al albor europeo}

16. En la esfera del Derecho de la Unión Europea ${ }^{24}$ no existe un concepto unívoco de consumidor puesto que cada Directiva contiene una definición del mismo a los efectos de su aplicación ${ }^{25}$. En cualquier caso, será considerado consumidor final aquel que no participa en actividades comerciales o profesionales y, que solo engloban los contratos celebrados para satisfacer las propias necesidades de consumo privado del individuo ${ }^{26 .}$

17. La finalidad no profesional, comercial o empresarial de la adquisición del bien o de la contratación de la prestación de un servicio será nuclear para su apreciación, por ende, la satisfacción de necesidades de carácter privado marcará la senda doméstica propia de las personas físicas, cuestión que, si bien, puede desconocerse en personas jurídicas de Derecho privado que realicen actividades extraprofesionales y que merezcan ser consideradas como consumidores o usuarios en determinadas relaciones jurídicas.

En el seno del Tribunal de Luxemburgo con la llegada del asunto Petruchová ${ }^{27}$ se aprecia una formidable calificación de consumidor a favor de los inversionistas; el juzgador europeo estima que, ni el volumen del dinero invertido, ni los riegos y pérdidas alcanzadas, ni tan siquiera la pericia del inversor, van a demoler los beneficios conferidos a los clientes inversionistas en las normas de Derecho internacional privado europeas. De igual modo, los conocimientos, la experiencia y, la cuantía y riesgo de la operación comercial no serán objeto de calificación para atribuir a una persona la cualidad de consumidor.

Exclusivamente, el punto de mira debe estar focalizado en la posición que este ostenta en el contrato y la finalidad del mismo, esto es, actuación ajena y completamente independiente a cualquier actividad profesional y, que el lucro obtenido de la transacción inversora sea, meramente, para uso particular ${ }^{28}$.

${ }^{23}$ D. Carrizo Aguado, "Posicionamiento de los consumidores en el Mercado único digital desde una perspectiva internacional privatista”, en L. García Álvarez y J.M. Martín Rodríguez (dirs.), El mercado único en la Unión Europea. Balance y perspectivas jurídico-politicas, Dykinson, Madrid, 2019, pp. 19-36.

${ }^{24}$ En atención a la reflexión de algún autor, la jurisprudencia del Tribunal de Justicia de la Unión conforma el actual Derecho de consumo, tanto en lo que se refiere a su aplicación, así como a su modificación, vid. M.D. PALACios GonzÁLez, "Tribunal de Justicia de la Unión Europea y Derecho del consumo en España", en P. Andrés SÁenz de Santamaría (coord.), Una contribución a la europeización de la ciencia jurídica: Estudios sobre la Unión Europea, Thomson Reuters-Civitas, Navarra, 2019 , p. 423

${ }^{25}$ A modo de ejemplo, la Directiva 2011/83/UE, de 25 de octubre, sobre derechos de los consumidores, determina como consumidor a la persona física que actúe con propósito ajeno a su actividad comercial, empresa, oficio o profesión (artículo 2.1.); la Directiva 2005/29/CE del Parlamento Europeo y del Consejo, de 11 de mayo de 2005, lo define como toda persona física con un propósito ajeno a su actividad económica, negocio, oficio o profesión (artículo 2.a.); la Directiva 2000/31/CE del Parlamento Europeo y del Consejo, de 8 de junio de 2000, lo conceptualiza como aquella persona física con un propósito ajeno a su actividad económica, negocio o profesión (artículo 2.e.). Ninguna Directiva de las mencionadas, entre otras, coincide en la literalidad del concepto. Lo que sí que tienen en común es que no incluyen a las personas jurídicas, suelen emplear el término subjetivo de "propósito", y el legislador comunitario tiende a la delimitación negativa (vid. J. CAYÓN DE LAS CUEVAS, "Configuración normativa y técnicas de tutela del consumidor en el Derecho de la Unión Europea" en J.L. TomiLlo URBINA (dir.) / J.J. Álvarez RuBio (coord.), La protección jurídica de los consumidores en el espacio Euroamericano, Comares, Granada, 2014, pp. 55-57).

${ }^{26}$ S. CÁmara LaPUENTE, "El concepto legal de «consumidor» en el Derecho privado europeo y en el Derecho español: aspectos controvertidos o no resueltos", Cuadernos de derecho transnacional, vol. 3, núm. 1, 2011, pp. 86-87.

${ }^{27}$ STJUE, de 3 de octubre de 2019, asunto C-208/18, Petruchová, EU:C:2019:825.

${ }^{28}$ D. CARrizo Aguado, "Nuevas coordenadas en las transacciones financieras internacionales: la teoría «Petruchová», Revista de Derecho del Sistema Financiero. Mercados, Operadores y Contratos, núm. 0, 2020, p. 345. 
18. Para ello, deben concurrir los requisitos que ha de reunir todo «consumidor» para merecer esta calificación jurídica y, en cualquier caso, no podrán realizar actividades de producción o de comercialización de bienes o servicios para el mercado ${ }^{29}$.

Así, se puede afirmar que, cuando una persona celebra un contrato para usos relacionados con su actividad profesional debe considerarse que se encuentra en igualdad de condiciones con su cocontratante ${ }^{30}$.

19. Se debe prestar especial atención, aunque sea someramente, a ciertos detalles acerca de la concepción de "consumidor medio" ofrecida por la jurisprudencia emanada del Tribunal de Justicia de la Unión. Será el asunto Gut Springenheide ${ }^{31}$, primer pronunciamiento del Tribunal de Luxemburgo, donde encontramos la identificación conceptual en el que es definido como aquel que está normalmente informado y razonablemente atento y perspicaz (apartado 31$)^{32}$. Un sector doctrinal sostiene que, esta idea supone una regresión en la tutela ofrecida al consumidor por las diferentes normas europeas. Por ello, se debe interpretar de manera restrictiva ${ }^{33}$ quedando residenciado de manera exclusiva al ámbito de las prácticas comerciales desleales, bien sean engañosas o agresivas ${ }^{34}$.

\section{Denominador común en la práctica judicial española}

20. Primeramente, conviene reseñar que a nivel interno, con la llegada de la Ley $3 / 2014$, de 27 de marzo ${ }^{35}$, por la que se modifica el Texto Refundido de la Ley General para la Defensa de los Consumidores y Usuarios ${ }^{36}$, el legislador español ofrece una nueva redacción a los artículos 3 y 4 de dicha norma, relativa a los conceptos de consumidor y empresario.

${ }^{29}$ J.M., Busto LAGo, "La posición del consumidor y del usuario en el Ordenamiento jurídico español” en AA.VV., Reclamaciones de consumo. Materiales para la construcción de un Tratado de Derecho de consumo, $4^{\mathrm{a}}$ ed., Aranzadi, Navarra, 2020, libro electrónico.

${ }^{30}$ STJCE de 20 enero de 2005, asunto C-464/01, Gruber, EU:C:2005:32 (vid. B. AÑoveros Terradas, "Delimitación de los supuestos internacionales en los que se justifica el forum actoris a favor del consumidor (A propósito de las sentencias del TJCE en los asuntos Johann Gruber y Petra Engler)", Diario La Ley, núm. 6264, 2005; J. VANnERom, Consumer Notion: Natural or Legal Persons and Mixed Contracts, Landmark cases of EU consumer law: in honour of Jules Stuyck, Intersentia, Cambridge, 2013, pp. 57-72).

${ }^{31}$ STJCE de 16 de julio de 1998, C-210/96, EU:C:1998:369.

${ }^{32}$ L. GonZÁlez VAQuÉ, "La noción de consumidor normalmente informado en la jurisprudencia del Tribunal de Justicia de las Comunidades Europeas: La Sentencia Gut Springenheide”, Derecho de los negocios, núm. 103, 1999, pp. 1-15; A. MARTíNEz Gutiérrez, "El carácter engañoso de la marca de empresa (comentario a la sentencia del Tribunal de Justicia de las Comunidades Europeas de 16 de Julio de 1998, asunto C-210/96)", Noticias de la Unión Europea, núm. 194, 2001, pp. 29-44; F. Palau Ramírez, "El consumidor medio y los sondeos de opinión en las prohibiciones de engaño en Derecho español y europeo. A raíz de la Sentencia del TJCE de 16 de julio de 1998, AS. C-210/96, GUT SPRINGENHEIDE", Actas de Derecho industrial $y$ derecho de autor, Tomo XIX, 1998, pp. 367-395.

${ }^{33}$ El concepto de "consumidor" es, en teoría, un concepto restrictivo. El futuro camina digitalmente hacia un consumo masivo online y en dicho paisaje social virtual es necesario que el TJUE abra vías de protección al consumidor de un modo evolutivo. En dicho contexto, es preciso que, en futuras reformas legislativas a nivel europeo, ex. gr. Reglamento (UE) 1215/2012, se incorporen los conceptos que el TJUE ha creado en relación con la competencia judicial en el sector del consumo transfronterizo: los conceptos de "acto de consumo", "consumidor", "profesional", y "actividad dirigida", por ejemplo, deberían dejar de ser conceptos jurisprudenciales para pasar a ser conceptos legales: Vid interesantísimo estudio de A-L. CALVo CARAVACA, "Los contratos de consumo en la jurisprudencia del TJUE. Últimas tendencias", Cuadernos de derecho transnacional, vol. 12, 2020, núm. 1, pp. 86-96.

${ }^{34}$ J. CAYÓN DE las Cuevas, "Configuración normativa y técnicas de tutela del consumidor en el Derecho de la Unión Europea”, en J.L. Tomillo Urbina, (dir.), J.J. Álvarez Rubio (coord.), La protección jurídica de los consumidores en el espacio Euroamericano, Comares, Granada, 2014, pp. 57-59.

${ }^{35}$ BOE núm. 287, de 30 de noviembre de 2007. La finalidad primera de la Ley 3/2014 es incorporar la Directiva 2011/83/ UE, de 25 de octubre, sobre los derechos de los consumidores (DOUE núm. 304, de 22 de noviembre de 2011). Interesa destacar, entre otros, los siguientes comentarios sobre la misma, vid: M.J. MARín LóPEZ, "La Directiva 2011/83/UE: esquema general, ámbito de aplicación, nivel de armonización y papel de los estados miembros", Revista CESCO de Derecho de Consumo, núm. 1, 2012, pp. 8-21; I. Raluca Stroie, "La Directiva 2011/83/UE, sobre los derechos de los consumidores, desde sus orígenes hasta la publicación en el diario oficial de la Unión Europea”, Revista CESCO de Derecho de Consumo, núm. 1, 2012, pp.1-7.

${ }^{36}$ BOE núm. 287, de 30 de noviembre de 2007. 
$\mathrm{Su}$ artículo 3 distingue entre consumidor persona física y consumidor persona jurídica o una entidad sin personalidad jurídica. Ello no supone contravenir el espíritu del legislador europeo, en razón de que, aun cuando sea una Directiva de máximos o de armonización plena, al tratarse de sujetos no incluidos en el ámbito de aplicación de la misma, es decir, materia no armonizada, los Estados miembros disponen de libertad regulatoria al respecto.

Sobre este particular, la doctrina más consolidada estima que, la finalidad del artículo 3 in fine es clara: incluir en el concepto de consumidor a algunos entes sin personalidad jurídica, como las comunidades de propietarios, y excluir a las personas jurídicas y entes sin personalidad que se constituyen con un claro ánimo de lucro, como son las sociedades mercantiles, o las comunidades de bienes constituidas por varios sujetos para operar en el mercado ${ }^{37}$.

21. En atención a la apreciación del juez español, la determinación de si un consumidor realiza una actividad inversora es una cuestión que debe de ser examinada en atención a las circunstancias concretas que se acrediten en cada uno de los supuestos de hecho que se enjuician, bien entendido que la carga de la prueba de la finalidad de la compraventa o prestación del servicio es diferente según el tipo de persona que contrate ${ }^{38}$.

El Alto Tribunal español entiende que, si se ignora cuál es el interés de los compradores y si, efectivamente, la intención es la explotación de un bien inmueble, sin residir en él, aunque fuese temporalmente, nos encontremos ante inversionistas y no con consumidores ${ }^{39}$.

22. No debe caer en olvido que, se excluyen del ámbito de protección de la Ley 57/1968 tanto al inversor profesional como al no profesional, con independencia de si la compra es sobre plano o en construcción ${ }^{40}$. También, se ha de considerar al comprador como un inversor ante la existencia de indicadores tales como, la residencia o el lugar de trabajo que resultan fiel prueba para destacar la finalidad inversora, dado que el comprador, así como sus familiares, residen y trabajan en el extranjero ${ }^{41}$.

Igualmente, si el comprador se trata de un promotor inmobiliario que había venido adquiriendo otras viviendas no podrá ampararse en la Ley supra mencionada al no tener la condición de consumidor, pues se trata de un inversor profesiona ${ }^{42}$. Asimismo, dos signos clave representan el quid en esta clase de operativa negocial internacional: la existencia de múltiples reservas de viviendas y la presencia de un comportamiento a cargo del comprador caracterizado no tanto por la pérdida económica, sino por la ausencia de la rentabilidad esperada ${ }^{43}$.

${ }^{37}$ M.J. MARín LóPEz, "El "nuevo" concepto de consumidor y empresario tras la Ley 3/2014, de reforma del TRLGDCU", Revista CESCO de Derecho de Consumo, núm. 9, 2014, pp. 13-15.

${ }^{38}$ En tal sentido, si fuese una persona jurídica debe de ser probada por la misma, por el contrario, si se trata de una persona física, la carga de probar la condición de inversor corresponde a la parte que la alega como hecho impeditivo de la demanda, esto es, a la demandada, conforme a las reglas generales de la carga de la prueba del artículo 217 LEC. Vid. fundamento núm. 17 de la SAP de Murcia, 20 de abril de 2020, ES:APMU:2020:647.

${ }^{39}$ ATS de 11 de noviembre de 2020, ES:TS:2020:10092A.

${ }^{40}$ STS de 11 de noviembre de 2020, ES:TS:2020:10173A; ATS de 14 de octubre de 2020, ES:TS:2020:8751A.

${ }^{41}$ STS de 3 de septiembre de 2020, ES:TS:2020:2806.

${ }^{42}$ STS de 1 de junio de 2016, ES:TS:2016:2567.

${ }^{43}$ STS de 3 de noviembre de 2014, ES:TS:2014:4250. 